\title{
Comparison of EGFR-TKI and chemotherapy in the first-line treatment of advanced EGFR mutation-positive NSCLC
}

\author{
O. FIALA ${ }^{1, *}$, M. PESEK 2 , J. FINEK ${ }^{1}$, L. BENESOVA 3 , Z. BORTLICEK ${ }^{4}$, M. MINARIK ${ }^{3}$
}

${ }^{1}$ Department of Oncology and Radiotherapy, University Hospital in Pilsen; ${ }^{2}$ Department of Tuberculosis and Respiratory Diseases, University Hospital in Pilsen; ${ }^{3}$ Center for Applied Genomics of Solid Tumors (CEGES), Prague; ${ }^{4}$ Institut of Biostatistics and Analyses, Masaryk University, Brno

*Correspondence: fiala.o@centrum.cz

Received October 22, 2012 / Accepted December 6, 2012

\begin{abstract}
Molecular targeted therapy based on EGFR tyrosine kinase inhibitors (EGFR-TKI) is currently a state of the art option for management of advanced stage NSCLC. Activating EGFR mutations are preferable for a good treatment response to EGFR-TKI. The presented retrospective study evaluated a clinical observation of EGFR-TKI aiming at its efficacy and safety in comparison to a standard chemotherapy in the first-line treatment of advanced stage NSCLC.

Total number of patients with advanced stage (IIIB, IV) EGFR mutation-positive NSCLC was 54 of which 23 were treated with EGFR-TKI and 31 patients with various chemotherapy regimens in the first line. The treatment efficacy was characterized in terms of disease control rate (DCR), progression-free survival (PFS) and overall survival (OS). The comparison of DCR was performed using Fisher's exact test and the differences in survival were tested using log-rank test.

DCR for EGFR-TKI treatment was $95.6 \%$ vs. $70.9 \%$ for chemotherapy ( $\mathrm{p}=0.032$ ). Median of PFS in patients treated with EGFR-TKI was 7.2 months vs. 2.5 months in patients treated with chemotherapy ( $<<0.001)$. Median of OS was 14.5 months vs. 21.4 months $(\mathrm{p}=0.729)$. EGFR-TKI was associated with higher incidence of skin rash and diarrhoea; chemotherapy was associated with higher incidence of haematologic adverse events and nausea or vomiting.

The analysis results showed a favourable DCR and PFS in patients treated with EGFR-TKI in the first line. The nonsignificant difference in OS could be attributed to a cross-over during the patient follow-up as well as the differences in performance status and age between both groups. EGFR-TKI is the optimal choice for the first-line treatment of EGFR mutation-positive NSCLC.
\end{abstract}

Key words: EGFR-TKI, first-line treatment, NSCLC, erlotinib, gefitinib, targeted treatment of NSCLC

Lung cancer is one of the most common human malignant diseases and the leading cause of cancer-related deaths worldwide [1]. The most common histological type is non-small cell lung cancer (NSCLC), which accounts for approximately $85 \%$ of lung cancers [2]. Molecular targeted therapy based on tyrosine kinase inhibitors, directed at the epidermal growth factor receptor (EGFR) is one of the novel options for management of advanced stage NSCLC. Two low-molecular EGFR tyrosine kinase inhibitors (EGFR-TKI), gefitinib and erlotinib, have been developed and approved for the treatment of advancedstage NSCLC. A presence of activating mutations in EGFR gene is currently the best predictor of therapeutic effect of EGFR-TKI in patients with advanced-stage NSCLC [3-12]. The reported frequency of activating EGFR mutations ranges from 5 to $20 \%$, predominantly in Asians, women, patients with adenocarcinoma histology and never-smokers [13-16]. The most common mutation types found by far are several deletions in EGFR exon 19 and one substitution in EGFR exon 21 (assigned as L858R) [17].

Results of randomized phase III clinical trials IPASS [18], OPTIMAL [19] and EURTAC [20] recently showed higher efficacy and also a better toxicity profile of the first-line treatment with EGFR-TKI (both, gefitinib and erlotinib) in comparison with standard chemotherapy regimens in population of EGFR mutation-positive NSCLC patients. These findings resulted to a change of recommendations for therapy of advanced stage NSCLC with the EGFR-TKI being recommended for the firstline treatment of EGFR mutation-positive patients [21].

We conducted a retrospective study based on clinical experience to evaluate efficacy and safety of erlotinib and gefitinib 


\section{Chemotherapy}

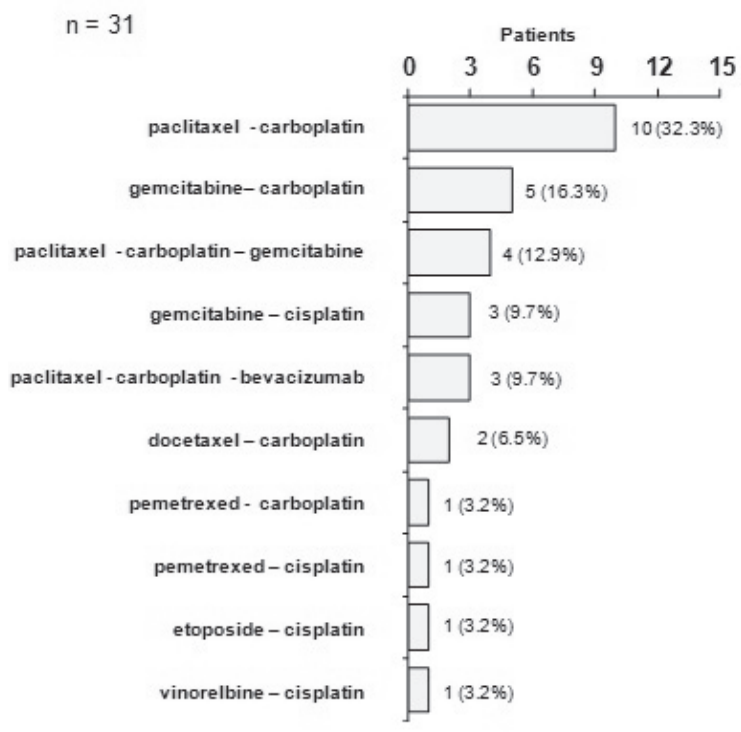

EGFR-TKI

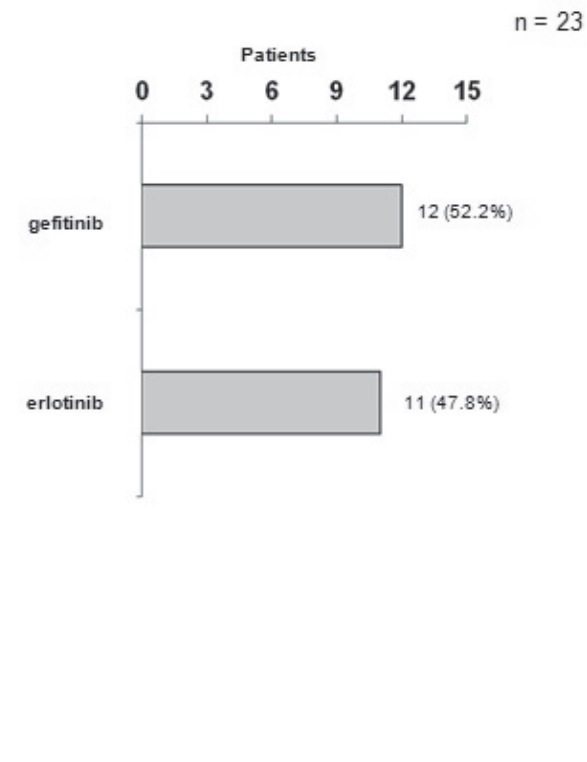

Figure 1. Treatment used in the first line.

in comparison with chemotherapy in the first-line treatment of advanced-stage EGFR mutation-positive NSCLC patients. The evaluations were mainly directed at comparison of the disease control rate (DCR), progression-free survival (PFS) and toxicity profile.

\section{Methods}

Study design and patients. We analysed data of patients with cytologically or histologically confirmed advanced-stage (IIIB, IV) NSCLC. Patients were diagnosed and treated at the Department of Tuberculosis and Respiratory Diseases in the University Hospital in Pilsen. In total, 613 patients were tested for presence of EGFR mutation. Of them 54 patients, who were tested positive for either exon 19 deletion or exon $21 \mathrm{~L} 858 \mathrm{R}$ point mutation were further evaluated in two groups [Fig. 1]. The first group consisted of 23 patients treated with EGFR-TKI in the first line administered at the standard approved doses; 11 patients treated with erlotinib (150 mg per day) and 12 patients treated with gefitinib (250 mg per day); the treatment was continued until disease progression or development of intolerable toxic effects. The second group consisted of 31 patients treated in the first line with one of standard chemotherapy regimens administered at the standard approved doses; 10 patients treated with paclitaxel /carboplatin (paclitaxel $175 \mathrm{mg} / \mathrm{m}^{2}$ on day 1 and carboplatin AUC 5 on day 1 every 3 weeks), 5 patients treated with gemcitabinelcarboplatin (gemcitabine $1000 \mathrm{mg} / \mathrm{m}^{2}$ on days 1 and 8, carboplatin AUC 5 on day 1 every 3 weeks), 4 patients treated with gemcitabin $\backslash$ paclitaxel $\backslash$ carboplatin (paclitaxel $175 \mathrm{mg} / \mathrm{m}^{2}$ on day 1 , carboplatin AUC 5 on day 1 and gem- citabine $1000 \mathrm{mg} / \mathrm{m}^{2}$ on day 1 and 8 every 3 weeks), 3 patients treated with gemcitabin $\mid c i s p l a t i n$ carboplatin (gemcitabine 1000 $\mathrm{mg} / \mathrm{m}^{2}$ on days 1 and 8 , cisplatin $80 \mathrm{mg} / \mathrm{m}^{2}$ on day 1 every 3 weeks), 3 patients treated with paclitaxel $\mid c a r b o p l a t i n \backslash$ bevacizu$\mathrm{mab}$ (paclitaxel $175 \mathrm{mg} / \mathrm{m}^{2}$ on day 1 , carboplatin AUC 5 on day 1 and bevacizumab $7.5 \mathrm{mg} / \mathrm{m}^{2}$ every 3 weeks), 2 patients treated with docetaxel lcarboplatin (docetaxel $75 \mathrm{mg} / \mathrm{m}^{2}$ on day 1 and carboplatin AUC 6 on day 1 every 3 weeks), 1 patient treated with pemetrexed $\backslash$ carboplatin (pemetrexed $500 \mathrm{mg} / \mathrm{m}^{2}$ on day 1 and carboplatin AUC 6 on day 1 every 3 weeks), 1 patient treated with pemetrexed /cisplatin (pemetrexed $500 \mathrm{mg} / \mathrm{m}^{2}$ on day 1 and cisplatin $75 \mathrm{mg} / \mathrm{m}^{2}$ on day 1 every 3 weeks), 1 patient treated with etoposidelcisplatin (etoposide $100 \mathrm{mg} / \mathrm{m}^{2}$ on day $1,2,3$ and cisplatin $120 \mathrm{mg} / \mathrm{m}^{2}$ on day 1 every 3 weeks) and 1 patient treated with vinorelbinelcisplatin (vinorelbine $25 \mathrm{mg} / \mathrm{m}^{2}$ on day 1 and 8 and cisplatin $80 \mathrm{mg} / \mathrm{m}^{2}$ on day 1 every 3 weeks). Chemotherapy was scheduled for up to six cycles unless development of intolerable toxic effects or disease progression occurred. The patients' characteristics are summarized in the Table 1. Patients who underwent sequential or concurrent chemoradiation were excluded from the analysis. After the end of first-line treatment, second-line treatment was noted revealing on a possible cross-over.

Clinical assessments and statistical methodology. Clinical follow-up controls including physical examination, plain chest skiagram and routine laboratory tests were performed every 3-4 weeks. CT or PET-CT controls were performed after 2 or 3 months of treatment with EGFR-TKI or after 2-3 cycles of chemotherapy. Treatment response was assessed using Response Evaluation Criteria in Solid Tumors (RECIST) [22]. 
Age of patients was compared by means of Mann-Whitney test. Fischer's exact test was used for comparison according to sex, smoking history, stage and Eastern Cooperative Oncology Group (ECOG) performance status (PS). Comparison of DCR was performed using Fischer's exact test. Evaluation of survival probabilities (PFS and OS) was performed based on Kaplan-Meier survival curves; all point estimates were accompanied with $95 \%$ confidence intervals. The differences in survival were tested using the log-rank test. Moreover, multivariable Cox proportional hazards model was used to evaluate influence of all potential predictive and prognostic factors on PFS and OS. As a level of statistical significance, $p$ value of 0.05 was used. Adverse events and serious adverse events were recorded and classified by grade according to the National Cancer Institute Common Terminology Criteria for Adverse Events version 3.0. [23]

EGFR mutation analysis. The tumor specimens acquired during an initial bronschoscopy examination were evaluated by a senior cytologist using a regular giemsa staining. In a few cases a tumor biopsy was processed into formalin-fixed paraffin embedded (FFPE) histology sections. The cytology slides or, eventually, the FFPE sections, were submitted for molecular genetic test being included detection of somatic mutations in EGFR gene. If it was necessary, tumour cells were carefully selected and removed from the samples by laser microdissection using P.A.L.M. microlaser instrument [Carl Zeiss MicroImaging GmbH, Germany]. The microdissected cells were collected directly into the PCR buffer and processed without a special DNA extraction step. In all other cases the DNA was extracted from tissue cells by a standard spin column procedure using JetQuick Tissue DNA Issolation Kit [GENOMED GmbH, Loehne, Germany]. The mutations in exons 19 and 21 of EGFR gene Genoscan EGFR kits [Genomac International, Prague, Czech Republic] utilizing a denaturing capillary electrophoresis (DCE) technique on ABI PRISM 3100 16-capillary genetic analyzer. Detected mutations were identified by regular DNA sequencing using a BigDye v 3.0 chemistry (Applied Biosystems, Foster City, CA). In rare cases, where the overall fraction of mutated DNA was below the $20 \%$ minimum required for DNA sequencing, mutation was identified indirectly after forming only a homoduplex fragment with a given known mutation reference standard.

\section{Results}

In a group treated with EGFR-TKI in the first line $(n=23)$, complete response (CR) was achieved in 3 (13.0\%), partial response (PR) in 7 (30.4\%) and stable disease (SD) in 12

Table 1. Basic clinical characteristics of patients

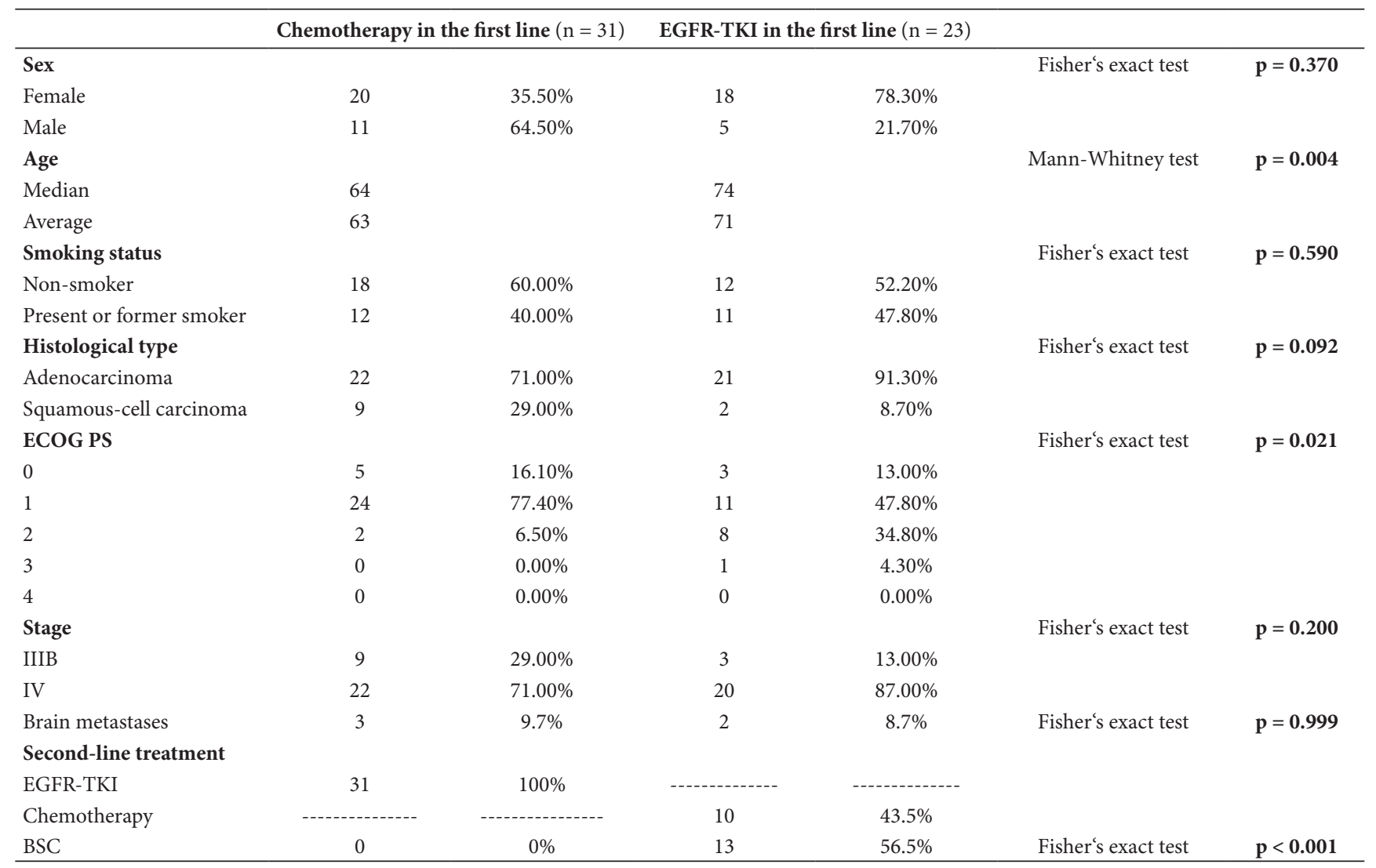




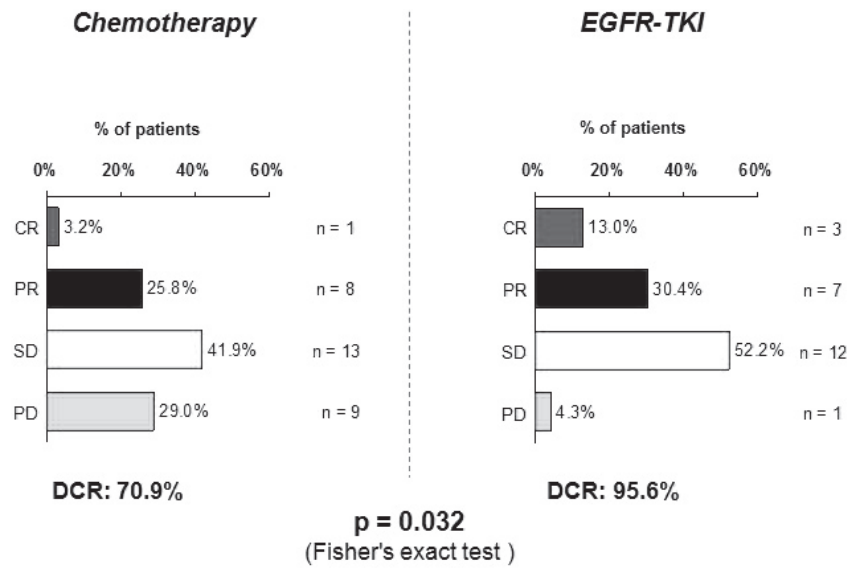

Figure 2. Comparison of best treatment response between EGFR M+ NSCLC patients treated with chemotherapy vs. EGFR M+ NSCLC patients treated with EGFR-TKI in the first line (complete response - CR; partial response - PR; stable disease - SD; progressive disease - PD).

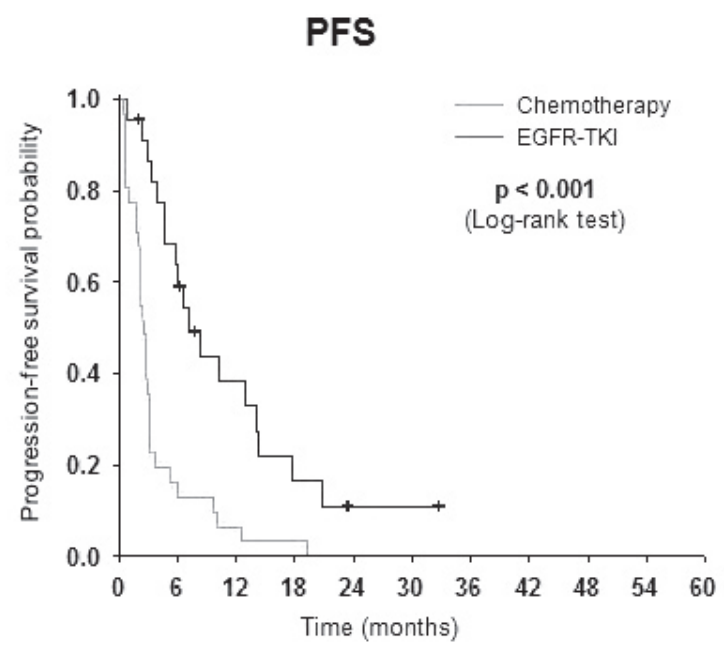

Figure 3. Comparison of progression-free survival (PFS) between EGFR M+ NSCLC patients treated with chemotherapy vs. EGFR M+ NSCLC patients treated with EGFR-TKI in the first line.

patients (52.2\%), for an overall disease control rate (DCR) of $95.6 \%$. In a group treated with chemotherapy in the first line $(\mathrm{n}=31), \mathrm{CR}$ was achieved in $1(3.2 \%), \mathrm{PR}$ in $8(25.8 \%), \mathrm{SD}$ in 13 patients (41.9\%), resulting in an overall disease control rate (DCR) of 70.9\%. The DCR difference between the two groups proved statistically significant ( $\mathrm{p}=0.032$ ) [Fig. 2]. Median of PFS in patients treated with EGFR-TKI was 7.2 months vs. 2.5 months in patients treated with chemotherapy with a statistical significance $(\mathrm{p}<0.001)$ [Fig. 3]. This trend was confirmed with multivariable Cox model, HR: 0.28 (95\% CI 0.15 - 0.53) $(\mathrm{p}<0.001)$. Median of OS in patients treated with EGFR-TKI was 14.5 months vs. 21.4 months in patients treated with chemotherapy $(\mathrm{p}=0.729)$ [Fig. 4]. This trend was confirmed

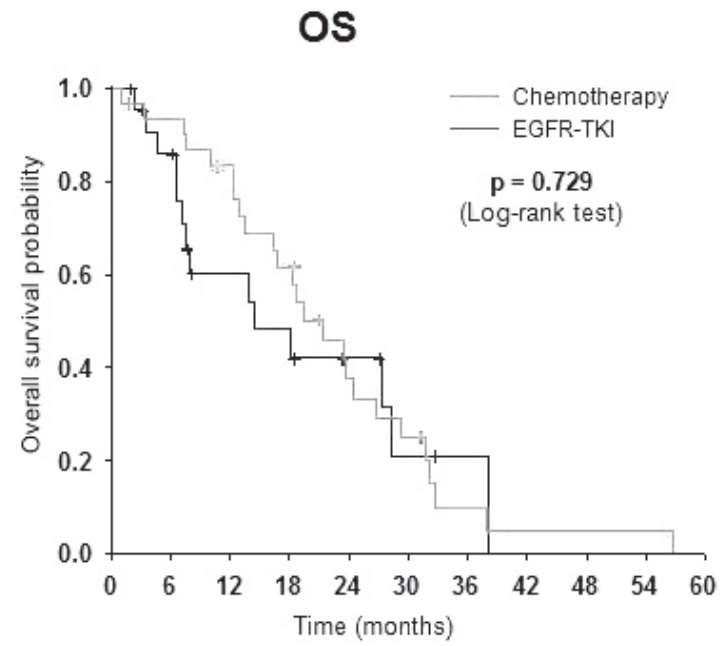

Figure 4. Comparison of overall survival (OS) between EGFR M+ NSCLC patients treated with chemotherapy vs. EGFR M+ NSCLC patients treated with EGFR-TKI in the first line.

with multivariable Cox model, HR: 1.03 (95\% IS 0.52 - 2.06) $(\mathrm{p}=0.932)$. The group treated with chemotherapy in the first line involved more patients in younger age categories (median 64 years vs. 74 years; $p=0.004$ ) and patients with better ECOG PS at the start of first-line treatment (PS 0: $16.1 \%$ vs. $13.0 \%$, PS 1: $77.4 \%$ vs. $47.8 \%$, PS $2: 6.5 \%$ vs. $34.8 \%$, PS $3: 0.0 \%$ vs. $4.3 \%$; $\mathrm{p}=0.021)$. There were not statistically significant differences in sex $(\mathrm{p}=0.370)$, smoking history $(\mathrm{p}=0.590)$, histological type $(\mathrm{p}=0.092)$ and clinical stage $(\mathrm{p}=0.200)$. In the group treated with chemotherapy in the first line 31 patients $(100 \%)$ were subsequently treated with EGFR-TKI in the second line. In the group treated with EGFR-TKI in the first line 10 patients (43.5\%) were treated with chemotherapy in the second line and 13 patients $(56.5 \%)$ were treated with best supportive care after ending of the first-line treatment. The difference in second-line treatment between compared groups proved statistically significant $(\mathrm{p}<0.001)$.

Neutropenia was reported in 1 patient $(4.3 \%)$ treated with EGFR-TKI vs. 14 patients (45.2\%) treated with chemotherapy $(\mathrm{p}=0.002)$ including $4(12.9 \%)$ events classified as grade 3 or 4 . Thrombocytopenia was reported in 2 patients $(8.7 \%)$ treated with EGFR-TKI vs. 8 patients $(25.8 \%)$ treated with chemotherapy $(\mathrm{p}=0.161)$ including $2(6.5 \%)$ events classified as grade 3 or 4 . Anemia was not reported in any patient treated with EGFR-TKI vs. 6 patients (19.4\%) treated with chemotherapy $(\mathrm{p}=0.032)$ including $2(6.5 \%)$ events classified as grade 3 or 4. No grade 3 or 4 haematologic adverse events were assesed in patiens treated with EGFR-TKI. Vomiting or nausea was reported in 3 patients (13.0\%) treated with EGFR-TKI vs. 10 patients $(32.3 \%)$ treated with chemotherapy $(\mathrm{p}=0.122)$; grade 3 or 4 was reported in 1 patient $(4.3 \%)$ treated with EGFR-TKI vs. 3 patients (9.7\%) treated with chemotherapy. Increased AST/ALT was reported in 9 patients (39.1\%) treated with 


\section{Chemotherapy EGFR-TKI}

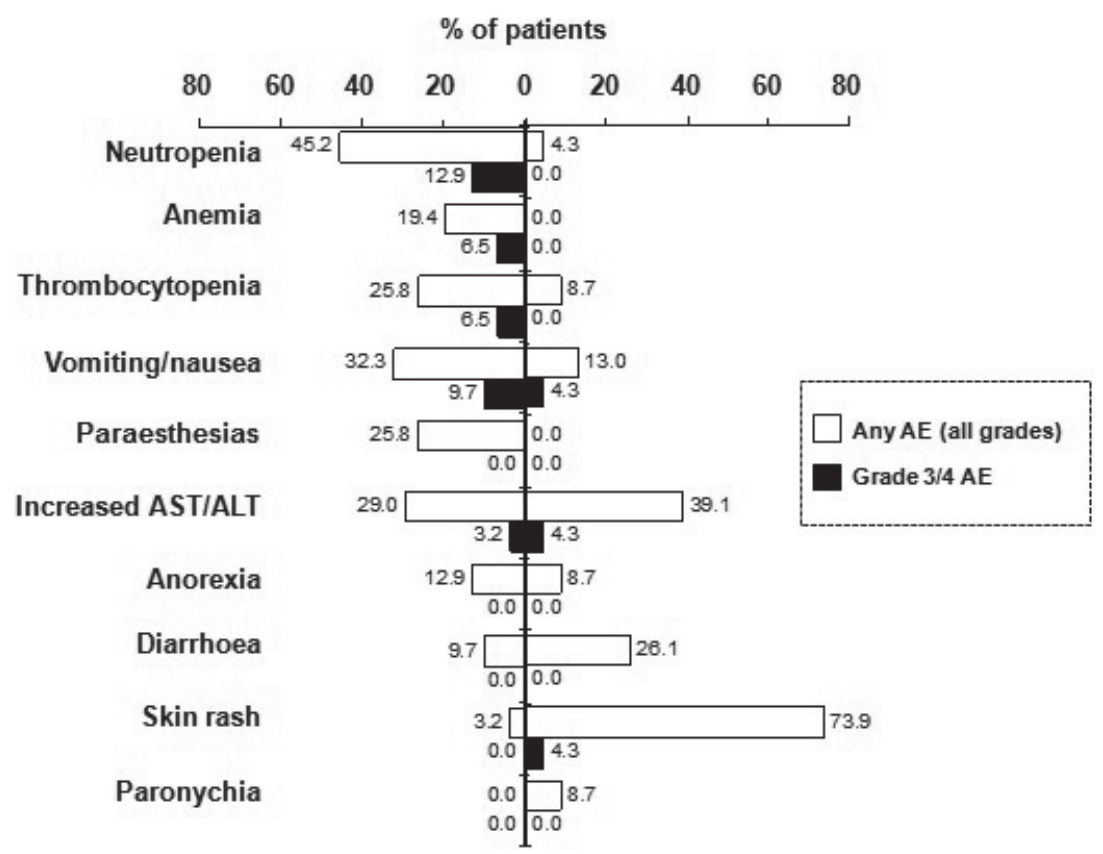

Figure 5. Comparison of most common adverse events (AE) between patients treated with chemotherapy vs. patients treated with EGFR-TKI in the first line.

EGFR-TKI vs. 9 patients (29.0\%) treated with chemotherapy $(\mathrm{p}=0.561)$; grade 3 or 4 was reported in 1 patient $(3.2 \%)$ treated with EGFR-TKI vs. 1 patient (4.3\%) treated with chemotherapy. Paraesthesias of any grade were not reported in any patient treated with EGFR-TKI vs. 8 patients $(25.8 \%)$ treated with chemotherapy $(\mathrm{p}=0.015)$; grade 3 or 4 were not reported. Skin rash was reported in 17 patients (73.9\%) treated with EGFR-TKI vs. 1 patient (3.2\%) treated with chemotherapy $(\mathrm{p}<0.001)$; grade 3 or 4 was reported in 1 patient $(4.3 \%)$ treated with EGFR-TKI vs. none patient treated with chemotherapy. Diarrhoea was reported in 6 patients $(26.1 \%)$ treated with EGFR-TKI vs. 3 patients (9.7\%) treated with chemotherapy $(\mathrm{p}=0.148)$, grade 3 or 4 was not recorded. Paronychia were recorded in 2 patients $(8.7 \%)$ treated with EGFR-TKI vs. none patient treated with chemotherapy $(\mathrm{p}=0.177)$; grade 3 or 4 were not reported. Anorexia was recorded in 4 patients (12.9\%) treated with EGFR-TKI vs. 2 patients treated with chemotherapy ( $p=0.999)$; grade 3 or 4 were not reported. The difference in grade 3 or 4 adverse events between compared groups was not statistically evaluated due to low number of events reported. No ILD-like events or cases of toxic death were reported in either group. Comparison of treatment associated adverse events is summarized in Figure 5.

\section{Discussion}

The study results proved statistically significant differences in DCR and PFS between patients treated in the first line with EGFR-TKI and patients treated with standard chemotherapy regimens in a selected population of patients with advanced-stage EGFR mutation-positive NSCLC. This result is in accordance with previously published phase III clinical trials [18-20].

When evaluating OS, it is necessary to mention the fact that, the difference in OS was not reached mainly due to crossover and significant difference in the second-line treatment between both compared groups. All patients in chemotherapy group were subsequently treated with EGFR-TKI, while only 10 patients $(43.5 \%)$ initially treated with EGFR-TKI later crossed to EGFR-TKI and 13 patients (56.5\%) received best supportive care. The difference in the second-line treatment is in a strong correlation with the fact that the group treated with EGFR-TKI in the first line involved more patients in older age categories $(\mathrm{p}=0.004)$ and patients with worse performance status $(\mathrm{p}=0.021)$. In comparison with previously performed studies comparing chemotherapy and EGFR-TKI in EGFR mutation-positive NSCLC patients [18-20] we found shorter survival (PFS, OS) for both groups, this could be explained by fact that patients included in our study were in worse performance status, higher age and those with symptomatic brain metastases were not excluded from evaluations.

The higher incidence of treatment-related adverse effects of chemotherapy, including haematologic toxicity (neutropenia, anemia, thrombocytopenia) as well as nausea or vomiting.

is a further confirmation of better toxicity profile of EGFRTKI. The higher incidence of diarrhoea as well as the skin 
rash in patients treated with EGFR-TKI has also previously been frequently reported. Moreover, the skin rash represents a potential predictive tool [24]. The more favourable toxicity profile of EGFR-TKI in comparison with standard chemotherapy is related to improvement of patient's quality of life, as reported in the IPASS trial [18].

Recently reported results of randomized phase III clinical trials [18-20] did not show major differences in OS mainly due to cross-over, which is consistent with results of our study. This finding indicates that the treatment with EGFR-TKI in patients harboring activating EGFR mutation is highly effective even in the second-line setting. The results of our study confirmed that treatment with EGFR-TKI is more effective accompanied with milder side-effects than chemotherapy in the first line suggesting that EGFR-TKI is currently the optimal choice for the first-line treatment of patients with advanced-stage EGFR mutation-positive NSCLC. Nonetheless, our data for crossover show still a reasonable survival if EGFR-TKI is received in the second line following a standard chemotherapy. An option of immediate chemotherapy with possible continuation by EGFR-TKI should therefore be considered in patients whose EGFR mutation status is not available at the time of the initial therapy decision making.

In our study we focused strictly on the presence of activating EGFR mutations, which is currently the exclusive biomarker routinely used for the first-line treatment decision making in the clinical practice. It should be mentioned that there are some other genetic alterations predicting de novo or acquired resistance to EGFR-TKI treatment such as EGFR T790M mutation in exon 20 [25-27] or genetic alterations resulting in activation of PI3K/AKT pathway [28, 29], but robust clinical data are still missing. Revealing mechanisms of resistance as well as looking for novel strategies to overcome resistance to EGFR-TKI is going to be a great challenge for the future research.

\section{Conclusion}

This retrospective direct comparison of efficacy and toxicity of EGFR-TKI and standard chemotherapy in the first-line treatment of patients with advanced-stage EGFR mutation-positive NSCLC based on clinical experience of single European department clearly showed higher DCR, longer PFS and more favourable toxicity profile of EGFR-TKI in comparison with chemotherapy. Genetic testing of activating EGFR mutations in patients with advanced-stage NSCLC plays a crucial role for the best first-line treatment decision.

Acknowledgments: This work was partially supported by the Czech Ministry of Health research project NR9087.

\section{References}

[1] PARKIN DM. Global cancer statistics in the year 2000. Lancet Oncol. 2001; 2(9): 533-43. http://dx.doi.org/10.1016/S14702045(01)00486-7
[2] BRAMBILLA E, TRAVIS WD, COLBY TV, CORRIN B, SHIMOSATO Y. The new World Health Organization classification of lung tumours. Eur Respir J. 2001; 18: 1059-68. http://dx.doi.org/10.1183/09031936.01.00275301

[3] LYNCH TJ, BELL DW, SORDELLA R, GURUBHAGAVATULA S, OKIMOTO RA, et al. Activating mutations in the epidermal growth factor receptor underlying responsiveness of non-small-cell lung cancer to gefitinib. N Engl J Med. 2004; 350: 2129-39. http://dx.doi.org/10.1056/NEJMoa040938

[4] PAEZ JG, JANNE PA, LEE JC, TRACY S, GREULICH H, et al. EGFR mutations in lung cancer: correlation with clinical response to gefitinib therapy. Science. 2004; 304: 1497-500. http://dx.doi.org/10.1126/science.1099314

[5] GANDHI J, ZHANG J, XIE Y, SOH J, SHIGEMATSU H, et al. Alterations in genes of the EGFR signaling pathway and their relationship to EGFR tyrosine kinase inhibitor sensitivity in lung cancer cell lines. PLoS One. 2009; 4: e4576. http://dx.doi. org/10.1371/journal.pone.0004576

[6] EBERHARD DA, JOHNSON BE, AMLER LC, GODDARD AD, HELDENS SL, et al. Mutations in the epidermal growth factor receptor and in KRAS are predictive and prognostic indicators in patients with non-small-cell lung cancer treated with chemotherapy alone and in combination with erlotinib. J Clin Oncol. 2005; 23: 5900-9. http://dx.doi.org/10.1200/ JCO.2005.02.857

[7] BONANNO L, SCHIAVON M, NARDO G, BERTORELLE R, BONALDI L, et al. Prognostic and predictive implications of EGFR mutations, EGFR copy number and KRAS mutations in advanced stage lung adenocarcinoma. Anticancer Res. 2010; 30: 5121-8.

[8] LIU HP, ISAAC WU HD, CHANG JW, WU YC, YANG HY, et al. Prognostic implications of epidermal growth factor receptor and KRAS gene mutations and epidermal growth factor receptor gene copy numbers in patients with surgically resectable non-small cell lung cancer in Taiwan. J Thorac Oncol. 2010; 5: 1175-84. http://dx.doi.org/10.1097/JTO.0b013e3181e2f4d6

[9] ZHU CQ, DA CUNHA SANTOS G, DING K, SAKURADA A, CUTZ JC, et al. Role of KRAS and EGFR as biomarkers of response to erlotinib in National Cancer Institute of Canada Clinical Trials Group Study BR.21. J Clin Oncol. 2008; 26: 4268-75. http://dx.doi.org/10.1200/JCO.2007.14.8924

[10] HIRSCH FR, VARELLA-GARCIA M, BUNN PA JR, FRANKLIN WA, DZIADZIUSZKO R, et al. Molecular predictors of outcome with gefitinib in a phase III placebo-controlled study in advanced non-small-cell lung cancer. J Clin Oncol. 2006; 24: 5034-42. http://dx.doi.org/10.1200/JCO.2006.06.3958

[11] BRUGGER W, TRILLER N, BLASINSKA-MORAWIEC M, CURESCU S, SAKALAUSKAS, et al. Biomarker analyses from the phase III placebo-controlled SATURN study of maintenance erlotinib following first-line chemotherapy for advanced NSCLC. J Clin Oncol. 2009; 27: 15s, (suppl; abstr 8020)

[12] PESEK M, BENESOVA L, BELSANOVA B, MUKENSNABL $\mathrm{P}$, BRUHA F, et al. Dominance of EGFR and insignificant KRAS mutations in prediction of tyrosine-kinase therapy for NSCLC patients stratified by tumor subtype and smoking status. Anticancer Res. 2009; 29: 2767-73. 
[13] ZHANG Z, STIEGLER AL, BOGGON TJ, KOBAYASHI S, HALMOS B, et al. EGFR-mutated lung cancer: a paradigm of molecular oncology. Oncotarget. 2010; 1: 497-514.

[14] SEQUIST LV, BELL DW, LYNCH TJ, HABER DA Molecular predictors of response to epidermal growth factor receptor antagonists in non-small-cell lung cancer. J Clin Oncol. 2007; 25: 587-95. http://dx.doi.org/10.1200/JCO.2006.07.3585

[15] GANDARA DR, LARA PN JR, MACK P, SCAGLIOTTI G, et al. Individualizing therapy for non-small-cell lung cancer: a paradigm shift from empiric to integrated decision-making. Clin Lung Cancer. 2009; 10: 148-50. http://dx.doi. org/10.3816/CLC.2009.n.020

[16] WEST H, LILENBAUM R, HARPOLE D, WOZNIAK A, SEQUIST L, et al. Molecular analysis-based treatment strategies for the management of non-small cell lung cancer. J Thorac Oncol. 2009; 4(9 Suppl 2): S1029-39. http://dx.doi. org/10.1097/JTO.0b013e3181b27170

[17] GAZDAR AF Activating and resistance mutations of EGFR in non-small-cell lung cancer: role in clinical response to EGFR tyrosine kinase inhibitors. Oncogene. 2009; 28 Suppl 1: S24-31. http://dx.doi.org/10.1038/onc.2009.198

[18] FUKUOKA M, WU YL, THONGPRASERT S, SUNPAWERAVONG P, LEONG SS, et al. Biomarker analyses and final overall survival results from a phase III, randomized, openlabel, first-line study of gefitinib versus carboplatin/paclitaxel in clinically selected patients with advanced non-small-cell lung cancer in Asia (IPASS). J Clin Oncol. 2011; 29: 2866-74. http://dx.doi.org/10.1200/JCO.2010.33.4235

[19] ZHOU C, WU YL, CHEN G, FENG J, LIU XQ, et al. Erlotinib versus chemotherapy as first-line treatment for patients with advanced EGFR mutation-positive non-small-cell lung cancer (OPTIMAL, CTONG-0802): a multicentre, open-label, randomised, phase 3 study. Lancet Oncol. 2011; 12: 735-42. http://dx.doi.org/10.1016/S1470-2045(11)70184-X

[20] ROSELL R, CARCERENY E, GERVAIS R, VERGNENEGRE A, MASSUTI B, et al. Erlotinib versus standard chemotherapy as fi rst-line treatment for European patients with advanced EGFR mutation-positive non-small-cell lung cancer (EURTAC): a multicentre, open-label, randomised phase 3 trial. Lancet Oncol 2012; 13: 239-46. http://dx.doi.org/10.1016/ $\underline{\text { S1470-2045(11)70393-X }}$
[21] National Comprehensive Cancer Network: NCCN Clinical Practice Guidelines in Oncology for Non-Small Cell Lung Cancer V.3.2011.

[22] THERASSE P, ARBUCK SG, EISENHAUER EA, WANDERS J, KAPLAN RS, et al. New guidelines to evaluate the response to treatment in solid tumors. European Organization for Research and Treatment of Cancer, National Cancer Institute of the United States, National Cancer Institute of Canada. J Natl Cancer Inst. 2000; 92: 205-16. http://dx.doi.org/10.1093/ inci/92.3.205

[23] Cancer Therapy Evaluation Program, Common Terminology Criteria for Adverse Events, Version 3.0.http://ctep.cancer.gov/ protocolDevelopment/electronic_applications/docs/ctcaev3. pdf

[24] FIALA O, PESEK M, FINEK J, KREJCI J, RICAR J, et al. Skin Rash as Useful Marker of Erlotinib Efficacy in NSCLC and Its Impact on Clinical Practice. Neoplasma. 2012 Oct 16. http://dx.doi.org/10.4149/neo 2013004

[25] GREULICH H, CHEN TH, FENG W, JÄNNE PA, ALVAREZ JV, et al. Oncogenic transformation by inhibitor-sensitive and -resistant EGFR mutants. PLoS Med. 2005; 2: e313. http:// dx.doi.org/10.1371/journal.pmed.0020313

[26] WU JY, WU SG, YANG CH, GOW CH, CHANG YL, et al. Lung cancer with epidermal growth factor receptor exon 20 mutations is associated with poor gefitinib treatment response. Clin Cancer Res. 2008; 14: 4877-82. http://dx.doi. org/10.1158/1078-0432.CCR-07-5123

[27] JANCARIKOVA D, PESEK M, BENESOVA L, TOPOLCAN O, HOLUBEC L Jr, et al. Acquired resistance of pulmonary adenocarcinoma to initially successful targeted therapy due to EGFR mutation T790M. Anticancer Res. 2007; 27: 1879-82.

[28] SOS ML, KOKER M, WEIR BA, HEYNCK S, RABINOVSKY $\mathrm{R}$, et al. PTEN loss contributes to erlotinib resistance in EGFRmutant lung cancer by activation of Akt and EGFR. Cancer Res. 2009; 69: 3256-61. http://dx.doi.org/10.1158/0008-5472. CAN-08-4055

[29] VIVANCO I, ROHLE D, VERSELE M, IWANAMI A, KUGA $\mathrm{D}$, et al. The phosphatase and tensin homolog regulates epidermal growth factor receptor (EGFR) inhibitor response by targeting EGFR for degradation. Proc Natl Acad Sci U S A. 2010; 107: 